Article

\title{
The In-Situ Synthesis of a 3D SnS/N-Doped Graphene Composite with Enhanced Electrochemical Performance as a Low-Cost Anode Material in Sodium Ion Batteries
}

\author{
Ning-Jing Song ${ }^{1}$ and Canliang $\mathrm{Ma}^{2, *}$ \\ 1 College of Chemistry and Chemical Engineering, Jinzhong University, Jinzhong 030619, China; \\ snj642370134@126.com \\ 2 Key Laboratory of Materials for Energy Conversion and Storage of Shanxi Province, Institute of Molecular \\ Science, Shanxi University, Taiyuan 030006, China \\ * Correspondence: macanliang@sxu.edu.cn
}

Received: 18 May 2019; Accepted: 18 June 2019; Published: 25 June 2019

check for updates

\begin{abstract}
SnS} / \mathrm{N}$-doped graphene (SnS/NG) composites are promising anode materials for sodium ion batteries. Generally, $\mathrm{SnS}$ is synthesized from $\mathrm{SnCl}_{2} \cdot 2 \mathrm{H}_{2} \mathrm{O}$. However, $\mathrm{SnCl}_{2} \cdot 2 \mathrm{H}_{2} \mathrm{O}$ is not suitable for large-scale production due to its high price. Compared with $\mathrm{SnCl}_{2} \cdot 2 \mathrm{H}_{2} \mathrm{O}, \mathrm{SnCl}_{4} \cdot 5 \mathrm{H}_{2} \mathrm{O}$ has a lower price, more stable chemical properties and better water solubility. Until now, there have been no related reports on the synthesis of $\mathrm{SnS}$ from $\mathrm{SnCl}_{4} \cdot 5 \mathrm{H}_{2} \mathrm{O}$. In this work, the fabrication of $\mathrm{SnS} / \mathrm{NG}$ in a facile, two-step process, which combines a hot water bath and thermal annealing and uses $\mathrm{SnCl}_{4} \cdot 5 \mathrm{H}_{2} \mathrm{O}$ as a precursor, is described. The mechanism of phase transformation in the direct synthesis of $\mathrm{SnS}$ from $\mathrm{Sn}^{4+}$ is also discussed in detail. Applying our methodology, SnS nanoparticles were grown in-situ on graphene sheets and wrapped by N-doped graphene sheets to form a 3D SnS/NG composite. With $35.35 \%$ content of graphene in the SnS/NG composite, the reversible specific capacity remained at $417.8 \mathrm{mAh} / \mathrm{g}$ at $1000 \mathrm{~mA} / \mathrm{g}$ after 100 cycles, exhibiting a high specific capacity and good cycling stability. In addition, the composite also had an excellent rate performance, with a specific capacity of $366.9 \mathrm{mAh} / \mathrm{g}$ obtained even at $5000 \mathrm{~mA} / \mathrm{g}$. Meanwhile, the fast sodium storage kinetics of SnS/NG were also analyzed, providing some theoretical support for further study.
\end{abstract}

Keywords: SnS/N-doped graphene; sodium ion battery; in-situ synthesis; phase transformation

\section{Introduction}

Motivated by sodium's similar physicochemical properties to lithium, abundance and low-cost, sodium ion batteries (SIBs) hold promise for a broad range of energy storage applications in the future [1]. Developing high-performance anode and cathode materials for SIBs is one of the most popular research subjects. Based on the theoretical stoichiometry of $\mathrm{Na}_{15} \mathrm{Sn}_{4}(847 \mathrm{mAh} / \mathrm{g})$-as SIBs anode-tin sulfide compounds are considered one type of promising material [2-4].

Owing to their large layer spacing ( $5.90 \AA$ for $\mathrm{SnS}_{2}$ and $4.33 \AA$ for SnS vs $1.02 \AA$ for $\left.\mathrm{Na}^{+}\right)$and high theoretical specific capacity, $\mathrm{SnS}_{2}$ and $\mathrm{SnS}$ have been intensively explored as anode materials for SIBs [5-7]. Compared with $\mathrm{SnS}_{2}$, SnS exhibits a smaller volume change ( $242 \%$ vs. $324 \%$ for $\mathrm{SnS}_{2}$ ) and less phase transformation upon sodiation/desodiation, which makes it more suited for repeated cycling operations-even though its intrinsic energy capacity is relatively low [8]. Zhou et al. [8] found that $\mathrm{SnS}_{2}$ could transform into $\mathrm{SnS}$ after an annealing step in an argon atmosphere, and that the transformed $\mathrm{SnS}$ showed enhanced sodium ion storage performance compared to that of $\mathrm{SnS}_{2}$. Currently, the regular synthesis method of SnS involves a hot water bath or hydrothermal reaction with 
$\mathrm{SnCl}_{2} \cdot 2 \mathrm{H}_{2} \mathrm{O}$ and thioacetamide (TAA) as precursors. Compared with $\mathrm{SnCl}_{2} \cdot 2 \mathrm{H}_{2} \mathrm{O}, \mathrm{SnCl}_{4} \cdot 5 \mathrm{H}_{2} \mathrm{O}$ has a lower price, more stable chemical properties and better water solubility. Thus, from the perspective of reducing the cost of electrode materials, it would be a better selection to synthesize SnS nanoparticles using $\mathrm{SnCl}_{4} \cdot 5 \mathrm{H}_{2} \mathrm{O}$ as the precursor in aqueous solution. Up to now, there have been no reports about the synthesis of SnS using $\mathrm{SnCl}_{4} \cdot 5 \mathrm{H}_{2} \mathrm{O}$ as a precursor.

In order to solve the rapid capacity fading, poor rate performance, serious agglomeration and volume expansion of pure SnS, application of SnS/carbon composites has been a common remedy as they can increase electrical conductivity, prevent the aggregation of nanoparticles and accommodate volume change $[9,10]$. Owing to its exceptional electrical, mechanical and chemical properties, graphene is often used as carrier for SnS. Based on this, the electrical conductivity and cycle stability of SnS/G composites has been shown to increase significantly [5,11]. However, strong Van der Waals forces and weak bonding between nonpolar graphene and polar tin sulfide can lead to the restacking of graphene and agglomeration of tin sulfide during repeated sodiation/desodiation processes. Different from pure graphene, $\mathrm{N}$-doped graphene (NG) may offer a stronger affinity to active materials and is easier to assemble into 3D structures with less restacking. Xiong et al. [7] prepared 3D SnS/NG by selecting commercial $\mathrm{SnS}_{2}$ and $\left(\mathrm{NH}_{4}\right)_{2} \mathrm{~S}$ as precursors and adding Poly (diallyldimethylammonium chloride)-graphene oxide (PDDA-GO) solution to the above solution, using dicyandiamide as a nitrogen source. Their 3D SnS/NG achieved better cycling performance than that of SnS/G.

In order to further reduce the cost of electrode materials and process complexity, we selected low-cost and water soluble $\mathrm{SnCl}_{4} \cdot 5 \mathrm{H}_{2} \mathrm{O}$ and TAA as precursors and common $\mathrm{NH}_{3} \cdot \mathrm{H}_{2} \mathrm{O}$ as a nitrogen source to prepare the 3D SnS/NG composite via a simple and controllable two-step method, which combined a hot water bath and thermal annealing. During the process, in-situ synthesis of SnS and $\mathrm{N}$-doping of graphene were realized simultaneously. As a result, SnS nanoparticles were anchored on the N-doped graphene sheets and wrapped by them. For SnS/NG, SnS offers high specific capacity, while graphene supplies excellent electrical conductivity. Meanwhile, owing to the in-situ synthesis and $\mathrm{N}$-doping of graphene, agglomeration was prevented and volume changes were alleviated significantly. Thus, SnS/NG possessed a high reversible capacity, an excellent rate capability and a stable cyclic performance, showing great potential as an anode material for SIBs. In this paper, the following three problems are discussed in detail: (1) The reaction mechanism from $\mathrm{Sn}^{4+}$ to $\mathrm{SnS}$ in the whole process, (2) the cycling stability and rate performance of SnS, SnS/G and SnS/NG as anode materials for SIBs, and (3) the fast sodium storage kinetics of SnS/NG.

\section{Materials and Methods}

A graphene oxide suspension $(1.5 \mathrm{mg} / \mathrm{mL})$ was prepared by sonicating a GO dispersion for $2 \mathrm{~h}$. Then, $0.601 \mathrm{~g}$ thioacetamide (TAA), $0.702 \mathrm{~g} \mathrm{SnCl} 4 \cdot 5 \mathrm{H}_{2} \mathrm{O}$ and $25 \mathrm{mg}$ polyvinyl pyrrolidone (PVP) was added to $40 \mathrm{~mL}$ of the graphene oxide suspension under sonication for $30 \mathrm{~min}$. Then, $20 \mathrm{~mL}$ of $\mathrm{NH}_{3} \cdot \mathrm{H}_{2} \mathrm{O}$ was added to the mixed solution before it was heated at $90{ }^{\circ} \mathrm{C}$ for $1 \mathrm{~h}$. After the solution was allowed to naturally cool to an ambient temperature, the product was collected by centrifugation and freeze-dried overnight. Finally, the obtained materials were heated to $600^{\circ} \mathrm{C}$ at a rate of $5^{\circ} \mathrm{C} / \mathrm{min}$ in an Ar atmosphere, and kept at $600^{\circ} \mathrm{C}$ for $120 \mathrm{~min}$. The obtained hybrid was marked as SnS/NG. In addition, $\mathrm{SnS} / \mathrm{G}$ was prepared without adding $\mathrm{NH}_{3} \cdot \mathrm{H}_{2} \mathrm{O}$, while pure $\mathrm{SnS}$ nanoparticles were prepared without adding $\mathrm{NH}_{3} \cdot \mathrm{H}_{2} \mathrm{O}$ or graphene.

The as-obtained samples were characterized using a scanning electron microscope (SEM, JSM-7001F, $3.0 \mathrm{kV}$, Japan), an X-ray diffractometer (XRD, Cu Ka radiation, D8 Advance, BRUKER/AXS, Germany), and an X-ray photoelectron spectrometer (XPS, Thermo ESCALAB 250XI, Thermo Fisher Scientific, USA). The nitrogen adsorption/desorption isotherms were recorded by a Micromeritics ASAP 2010 surface area analyzer. Thermo-gravimetric analysis (TGA, STA 1640, Stanton Redcroft Inc., UK) was performed at a heating rate of $10{ }^{\circ} \mathrm{C} \mathrm{min}^{-1}$ in air. The electrochemical properties were measured using coin-type (CR2032) half cells. To produce a slurry, $80 \mathrm{wt} . \%$ samples, $10 \mathrm{wt} . \%$ acetylene black and $10 \mathrm{wt} . \%$ carboxymethyl cellulose were mixed in deionized water. This slurry was then uniformly 
loaded on a $\mathrm{Cu}$ foil with a doctor blade to prepare a film-type electrode. The sample was dried at $100{ }^{\circ} \mathrm{C}$ under vacuum for $12 \mathrm{~h}$, and then cut into circular electrodes. The cells were assembled in an Ar-filled glove box (Dellix Co., Chengdu, China) with sodium foil as both the reference and counter electrode, glass fiber as the separator and a solution of $1.0 \mathrm{M} \mathrm{NaClO}_{4}$ in ethylene carbonate (EC): dimethyl carbonate (DMC): ethyl methyl carbonate $(E M C)=1: 1: 1$ vol. $\%$ with $2.0 \%$ fluoroethylene carbonate (FEC) additive as the electrolyte. All electrochemical measurements were carried out on a battery testing system (Neware Co., Shenzhen, China) in the potential range of $0.01 \mathrm{~V}$ to $3 \mathrm{~V}$. Cyclic voltammetry (CV) measurements were made using an IM6 electrochemical testing station running at $0.1 \mathrm{mVs}^{-1}$ from the open circuit potential to $0.01 \mathrm{~V}$, and then back to $2.5 \mathrm{~V}$.

\section{Results and Discussion}

As shown in Figure 1, SnS/NG was prepared by a facile procedure involving a hot water bath and thermal annealing. Firstly, $\mathrm{SnCl}_{4} \cdot 5 \mathrm{H}_{2} \mathrm{O}$ and TAA were dissolved in graphene oxide (GO) in order to prepare a suspension of mixed solution. During the hot water bath, as $\mathrm{NH}_{3} \cdot \mathrm{H}_{2} \mathrm{O}$ was added to the above suspension, nitrogen atoms were doped into GO sheets, which provided more defect sites for the formation of tin sulfide compound particles. Meanwhile, $\mathrm{Sn}^{4+}$ was partly reduced to form $\mathrm{SnS}$ in the presence of $\mathrm{NH}_{3} \cdot \mathrm{H}_{2} \mathrm{O}$, while the remainder generated $\mathrm{SnS}_{2}$, as confirmed by the XRD results. Therefore, $\mathrm{SnS}$ and $\mathrm{SnS}_{2}$ were successfully grown in-situ on $\mathrm{N}$-doped graphene oxide sheets. Secondly, during the process of high temperature thermal reduction, $\mathrm{N}$-doped graphene oxide nanosheets were reduced to N-doped graphene nanosheets, while $\mathrm{SnS}_{2}$ was reduced to $\mathrm{SnS}$. As a result, $\mathrm{SnS}$ was grown in-situ on $\mathrm{N}$-doped graphene sheets, forming a 3D SnS/NG composite.
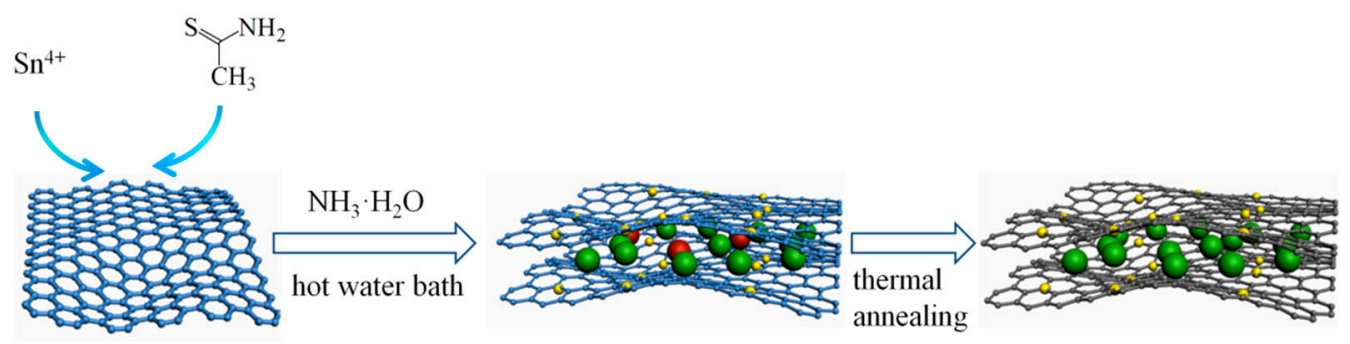

- $\bigcirc \mathrm{SnS} \odot \mathrm{SnS}_{2}$

Figure 1. Schematic of synthesis of SnS/N-doped graphene (NG).

XRD was used to identify the phase compositions and structure of pure SnS, SnS/G, and SnS/NG before annealing and SnS/NG after annealing (Figure 2a). For SnS and SnS/NG after annealing, all of the high crystallinity peaks could be indexed to SnS (PDF\#65-3812). The lattice distance of SnS is $2.84 \AA$, which is larger than the size of $\mathrm{Na}^{+}$at $1.02 \AA$. Thus, the lattices were considered fit for hosting $\mathrm{Na}^{+}$. No apparent graphene diffraction peaks at $2 \theta=20-30^{\circ}$ were observed, which was in agreement with the findings of Reference [7]. For SnS/NG before annealing, the peaks located at $21.946^{\circ}$ and $25.952^{\circ}$ could be indexed as SnS (PDF\#65-3812), meanwhile, the peak located at $15.029^{\circ}$ could be indexed as $\mathrm{SnS}_{2}$ (PDF\#23-0677), which was consistent with the results obtained by References [11] and [12]. A possible explanation for this phenomenon is that a portion of $\mathrm{Sn}^{4+}$ was reduced to $\mathrm{Sn}^{2+}$ during the hot water bath reaction-owing to the existence of $\mathrm{NH}_{3} \cdot \mathrm{H}_{2} \mathrm{O}$ - while the rest of the $\mathrm{Sn}^{4+}$ was reduced to $\mathrm{Sn}^{2+}$ during the thermal reduction. For $\mathrm{SnS} / \mathrm{G}$, a peak located at $16.3^{\circ}$ could be indexed as $\mathrm{SnS}_{2}$ (PDF\#23-0677). Therefore, through comparison of SnS/G and SnS/NG after annealing, ammonia reduction and thermal annealing were the determining factors in the complete reduction of $\mathrm{Sn}^{4+}$ to $\mathrm{Sn}^{2+}$, and both reduction processes were indispensable. 
(a)

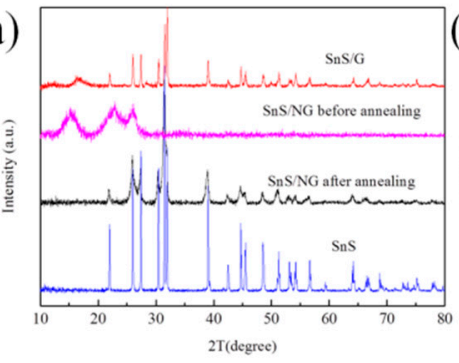

(d)

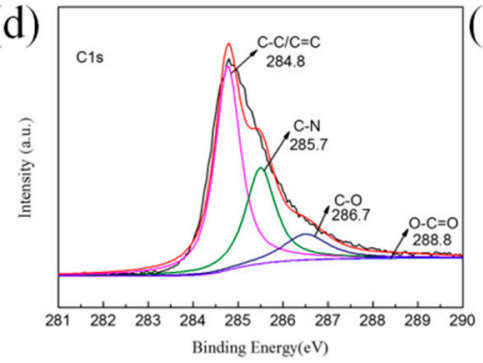

(b)

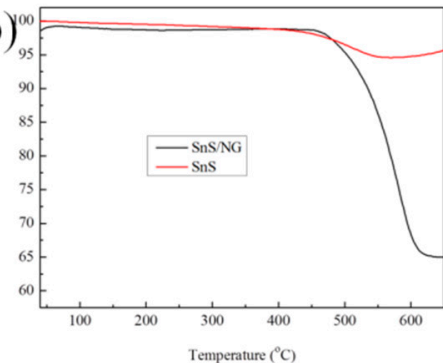

(e)

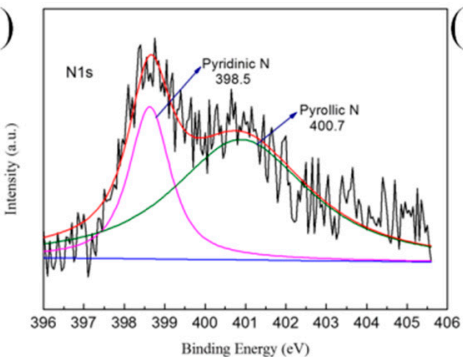

(c)

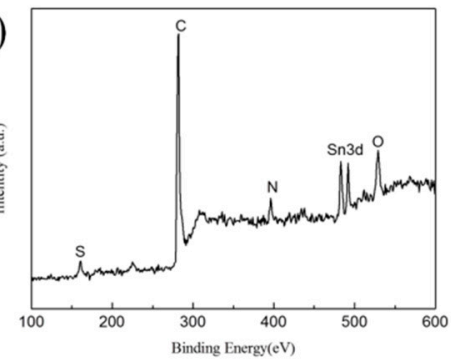

(f)



Figure 2. (a) X-ray diffraction (XRD) patterns of SnS, SnS/graphene (SnS/G), and SnS/NG before and after heat treatment; (b) thermo-gravimetric analysis (TGA) curve of the SnS/NG and SnS hybrid in air; (c) survey X-ray photoelectron spectrometer (XPS) spectra; and high-resolution XPS spectra of (d) C 1s, (e) N 1s and (f) Sn 3d of SnS/NG.

The content of graphene among SnS/NG was estimated by TGA. As shown in Figure 2b, when the temperature reached $455^{\circ} \mathrm{C}$, the weight of SnS/NG decreased sharply. This could be attributed to a loss of graphene. In addition, the weight of SnS also decreased slightly, which could be due to the existence of a little PVP. The content of graphene in the SnS/NG was calculated as $30.35 \%$.

XPS was carried out to determine the state of the chemical bonds in the samples. As shown in Figure 2c, the survey XPS spectra of SnS/NG had a pronounced N1 peak at $400.0 \mathrm{eV}$; the content of N was found to be $5.37 \%$ by elemental analysis from the survey spectrum, implying that the graphene sheet was successfully doped with $\mathrm{N}$. The content of $\mathrm{O}$ was $10.68 \%$ in $\mathrm{SnS} / \mathrm{NG}$, lower than pure graphene oxide, which could be attributed to the observed reduction of graphene oxide. High-resolution XPS spectra of $C 1$ s was fitted into four peaks with binding energies (B.E.) at about 284.4, 285.7, 286.7 and $288.8 \mathrm{eV}$, attributable to $\mathrm{C}-\mathrm{C} / \mathrm{C}=\mathrm{C}, \mathrm{C}-\mathrm{N}, \mathrm{C}-\mathrm{O}$ and $\mathrm{O}-\mathrm{C}=\mathrm{O}$, respectively (Figure $2 \mathrm{~d}$ ). Our result was in agreement with that of Reference [7]. The content of $\mathrm{C}-\mathrm{C} / \mathrm{C}=\mathrm{C}, \mathrm{C}-\mathrm{N}, \mathrm{C}-\mathrm{O}$ and $\mathrm{O}-\mathrm{C}=\mathrm{O}$ was $44.11 \%, 24.27 \%, 9.87 \%$ and $0.85 \%$, respectively. From this, we found that $\mathrm{N}$ in SnS/NG combined with $\mathrm{C}$ to form $\mathrm{C}-\mathrm{N}$. As shown in Figure 2e, N 1s fitted into two peaks, indicating two kinds of $\mathrm{N}$ existed, namely pyridinic $\mathrm{N}(398.5 \mathrm{eV})$ and pyrrolic $\mathrm{N}(400.7 \mathrm{eV})$. In addition, the peak of $\mathrm{Sn} 3 \mathrm{~d}_{2 / 5}$ was located at $486.9 \mathrm{eV}$, corresponding to SnS (Figure 2f), which was consistent with the result of the XRD spectrum. Thus, we were able to confirm that SnS/NG was successfully synthesized by the simple two-step method.

The $\mathrm{N}_{2}$ adsorption/desorption isotherms of SnS/NG, SnS/G, SnS/NG before annealing and SnS are shown in Figure 3. The Brunauer-Emmett-Teller (BET) surface area of SnS was $8.521 \mathrm{~m}^{2} \mathrm{~g}^{-1}$ (Figure 3d). With the addition of graphene, the BET surface area of SnS/NG, SnS/G and SnS/NG before annealing increased to $25.743 \mathrm{~m}^{2} \mathrm{~g}^{-1}$ (Figure 3a), $17.180 \mathrm{~m}^{2} \mathrm{~g}^{-1}$ (Figure 3b) and $12.309 \mathrm{~m}^{2} \mathrm{~g}^{-1}$ (Figure 3c), respectively; the major contributor to surface area was the graphene sheets. Compared to SnS/NG before annealing and SnS/G, SnS/NG had the highest specific surface area, which could be attributed to the removal of oxygen-containing functionality, N-doping of GO during the annealing process and a chemical reduction. This was consistent with our XPS results. 
(a)

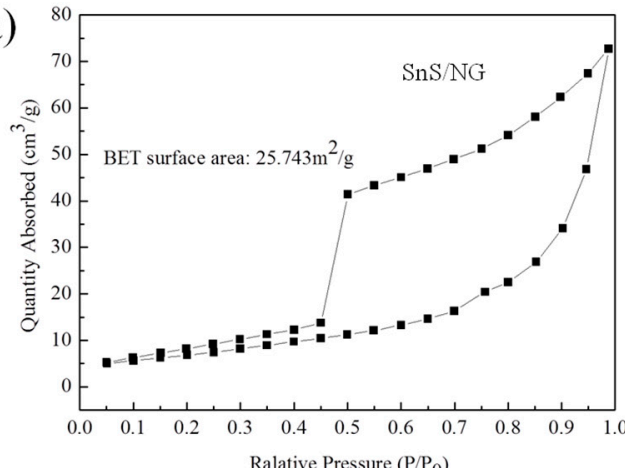

(c)

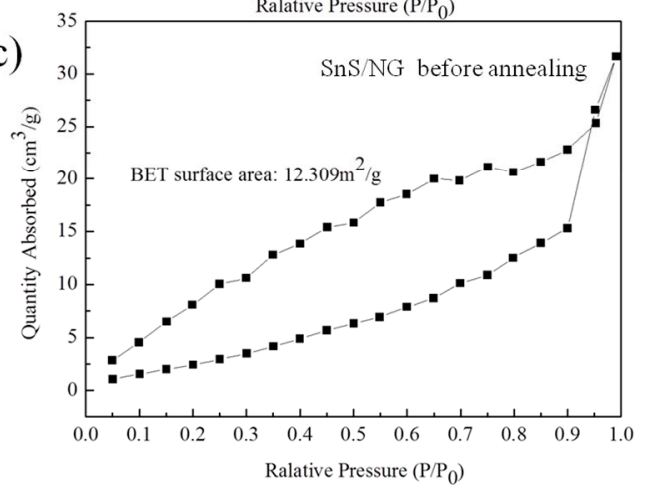

(b)

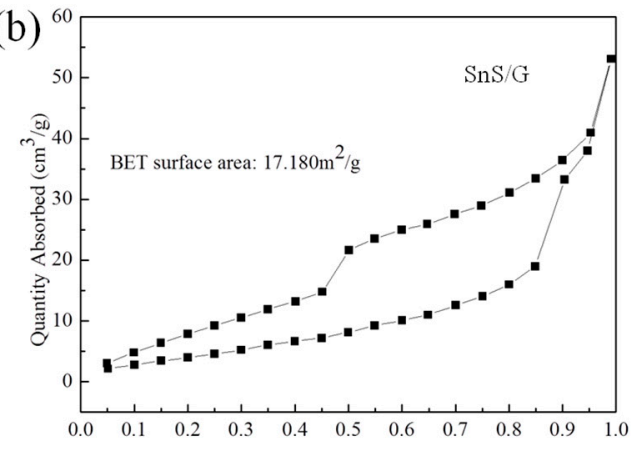

(d)

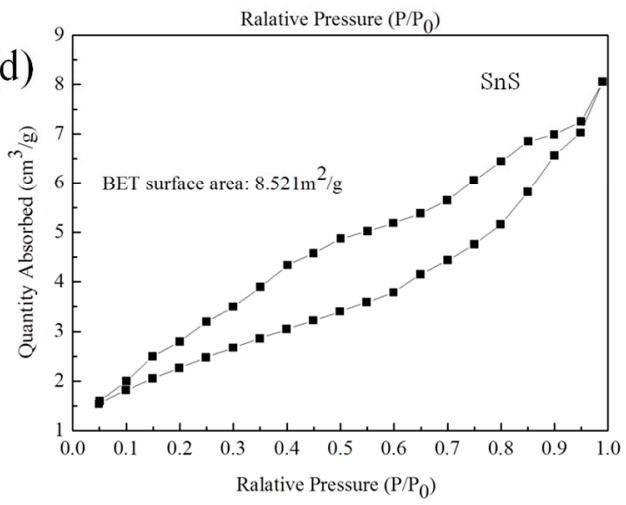

Figure 3. $\mathrm{N}_{2}$ isotherms and calculated Brunauer-Emmett-Teller (BET) specific surface area of (a) SnS/NG, (b) SnS/G, (c) SnS/NG before annealing and (d) SnS.

SEM images of SnS/NG, SnS/G and SnS are shown in Figure 4. As shown in Figure 4a, for SnS/NG, the SnS nanoparticles were wrapped by the graphene sheets and uniform in size. For SnS/G, the stacking of graphene sheets was more obvious (Figure $4 \mathrm{~b}$ ), while pure SnS nanoparticles exhibited dense agglomeration (Figure 4c). Compared with pure SnS nanoparticles and SnS/G, the N-doped graphene sheets offered more active sites for $\mathrm{SnS}$, and thus could more effectively resist the aggregation of SnS nanoparticles during the preparation process.

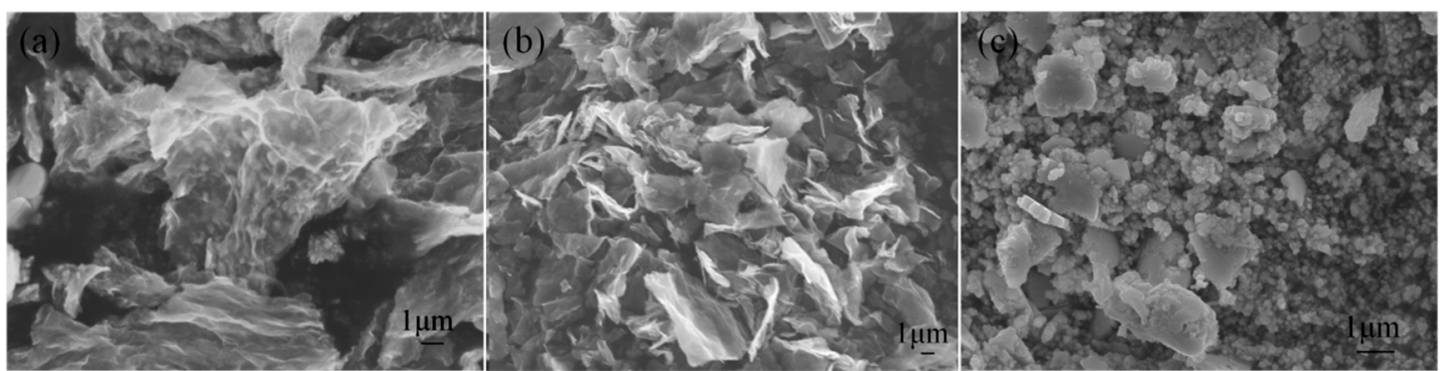

Figure 4. Scanning electron microscope (SEM) images of (a) SnS/NG, (b) SnS/G, and (c) SnS.

Figure 5a shows the cyclic voltammetry $(\mathrm{CV})$ tests at different scan rates, which was used to better understand the fast sodium storage kinetics of SnS/NG. The shape is well preserved, with increasing scan rate from 0.5 to $2.0 \mathrm{mV} / \mathrm{s}$. The peak at $0.6 \mathrm{~V}$ corresponds to alloying and conversion reaction kinetics that form the $\mathrm{Na}_{15} \mathrm{~S}_{4}$ phase [6]. The peak at $1.17 \mathrm{~V}$ refers to the reformation of $\mathrm{SnS}$. In CV measurements, the total current measured under a potential sweep rate may be interpreted as the sum of the current in relation to the slow diffusion-controlled process (idiff) and the current required to charge a double layer at the electrolyte interface or to initiate fast faradaic reactions on an exposed electrode surface (icap) [13]. Thus, quantitatively distinguishing between capacitive processes and diffusion-controlled intercalation processes is highly desirable for a better understanding of the underlying charge storage mechanism, which aids in the selection of materials and device design [14]. 



Figure 5. Quantitative capacitive analysis of sodium storage behavior of SnS/NG. (a) Cyclic voltammetry $(\mathrm{CV})$ curves at different scan rates. (b) Plots of $v^{1 / 2}$ vs. $i / v^{1 / 2}$. (c) Capacitive contribution at $0.8 \mathrm{mV} / \mathrm{s}$. (d) Normalized contribution ratio of capacitive capacities at different scan rates.

The relationship between $i(\mathrm{~V})$ and $v^{1 / 2}$ may be described using the following equation (1):

$$
\frac{i(\mathrm{~V})}{v^{\frac{1}{2}}}=k_{1} v^{\frac{1}{2}}+k_{2}
$$

The constants $k_{1}$ and $k_{2}$ can be evaluated from the slope and intercept, respectively, of a linear plot of $i(\mathrm{~V}) / v^{1 / 2}$ versus $v^{1 / 2}$. Consequently, it is possible to quantitatively differentiate the current contribution from the capacitive effect $\left(k_{1} v\right)$ from diffusion-controlled intercalation processes $\left(k_{2} v^{1 / 2}\right)$ (Figure 5b) [14].

In Figure $5 c$, the percentage of capacitive contribution to the current at a fixed voltage may be quantitatively determined by separating the current response, $i$, from the diffusion-controlled and capacitive contribution at the corresponding voltage [15,16]. As a result, $57.3 \%$ of the total capacity was identified as the capacitive contribution at $0.8 \mathrm{mV} / \mathrm{s}$. With an increase in scan rate, the diffusion contribution depressed, while the capacitive contribution-as expected-increased (Figure 5d). At $2.0 \mathrm{mV} / \mathrm{s}$, the capacitive contribution tended to be stable at $69.92 \%$. Thus, for the fast sodium storage kinetics of SnS/NG, the capacity was mainly drawn from the capacitive contribution.

The initial discharge/charge profiles of SnS/NG at $200 \mathrm{~mA} / \mathrm{g}$ are shown in Figure 6a. The discharge capacity and charge capacity at the first cycle were found to be 612.8 and $647.1 \mathrm{~mA} \mathrm{~h} / \mathrm{g}$, respectively. The electrode showed good reversibility after a stable solid electrolyte interphase (SEI) had been formed. For the second and third cycle, the voltage profiles overlapped, while the coulombic efficiency was determined to be $100 \%$. At the current density of $1000 \mathrm{~mA} / \mathrm{g}$, the long-time cycle stability of SnS, SnS/G and SnS/NG are shown in Figure 6b. In the sixth cycle, the specific capacity of SnS/NG, SnS/G and SnS were 504.0, 566.3 and $492.1 \mathrm{mAh} / \mathrm{g}$, respectively, while after 100 cycles, the specific capacity of SnS/NG, SnS/G and SnS were $417.8,355.6$ and $157.9 \mathrm{mAh} / \mathrm{g}$, respectively. We ascribed the rapid decline of the capacity for $\mathrm{SnS}$ to low electrical conductivity of $\mathrm{SnS}$ and severe aggregation during the discharge/charge cycles. Compared with SnS/G, SnS/NG exhibited better cycle performance. 
Obviously, the N-doped graphene sheets had an important role in promoting the cycle stability of $\mathrm{SnS} / \mathrm{NG}$. In order to verify the influence of current density on the cycle stability of SnS/NG, $200 \mathrm{~mA} / \mathrm{g}$ and $1000 \mathrm{~mA} / \mathrm{g}$ were selected. In the first cycle, the capacity of pure SnS and SnS/NG were $596.65 \mathrm{mAh} / \mathrm{g}$ and $596.34 \mathrm{mAh} / \mathrm{g}$, respectively, with the capacity contribution of $\mathrm{N}$-doped graphene to the composite determined as $180.77 \mathrm{mAh} / \mathrm{g}$, which was calculated using:

$$
\begin{aligned}
\text { Capacity }_{\mathrm{NG}} & =\text { Capacity }_{\mathrm{SnS} / \mathrm{NG}}-\text { Content }_{\mathrm{SnS}} \cdot \text { Capacity }_{\mathrm{SnS}} \\
& =596.34 \mathrm{mAh} / \mathrm{g}-69.95 \% \times 596.65 \mathrm{~mA} / \mathrm{g}=180.77 \mathrm{mAh} / \mathrm{g}
\end{aligned}
$$
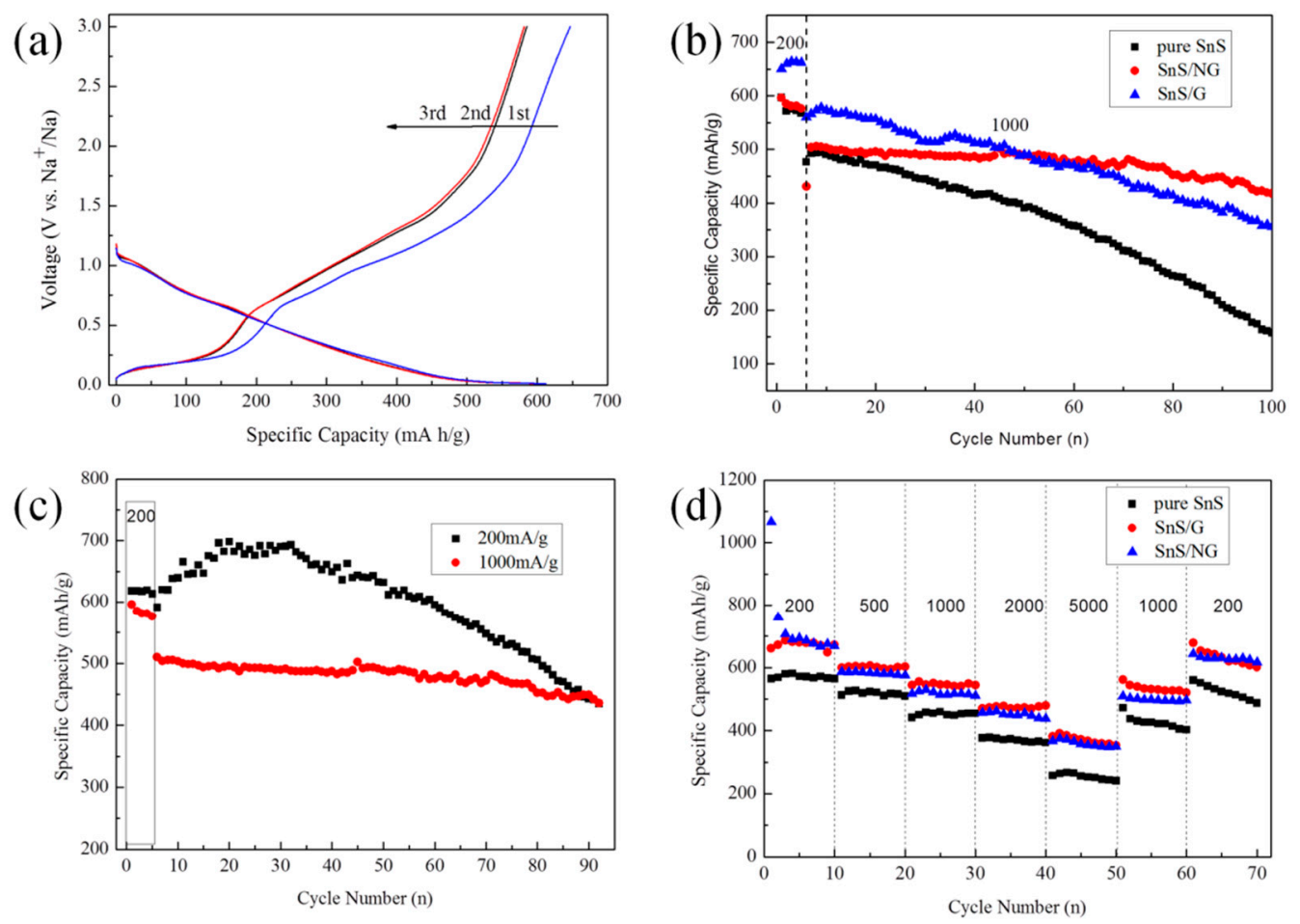

Figure 6. (a) Discharge/charge profiles of SnS/NG at different cycles at $200 \mathrm{~mA} / \mathrm{g}$. (b) Cycle stability of SnS/NG, SnS/G and SnS at $1000 \mathrm{~mA} / \mathrm{g}$. (c) Cycle stability of SnS/NG at $1000 \mathrm{~mA} / \mathrm{g}$ and $200 \mathrm{~mA} / \mathrm{g}$. (d) Rate performance of SnS/NG, SnS/G and SnS.

As shown in Figure $6 c$, the cycle stability of SnS/NG at $1000 \mathrm{~mA} / \mathrm{g}$ was better than that at $200 \mathrm{~mA} / \mathrm{g}$. After 100 cycles, the capacity retention of SnS/NG at $1000 \mathrm{~mA} / \mathrm{g}$ and $200 \mathrm{~mA} / \mathrm{g}$ were $80.1 \%$ and $57.4 \%$, respectively. Thus, at a higher current density, SnS/NG had better cycling stability, indicating strong potential for its use in high-power SIBs. Figure $6 \mathrm{~d}$ shows the rate performance of SnS/NG, SnS/G and $\mathrm{SnS}$, in which the current densities increase step-wise from $200 \mathrm{~mA} / \mathrm{g}$ to $5000 \mathrm{~mA} / \mathrm{g}$, and finally back to $200 \mathrm{~mA} / \mathrm{g}$. During the process, SnS/NG and SnS/G consistently outperformed SnS. In the first 10 cycles, the specific capacity of SnS/NG was $683.8 \mathrm{mAh} / \mathrm{g}$ at $200 \mathrm{~mA} / \mathrm{g}$, while at a current density of $5000 \mathrm{~mA} / \mathrm{g}$, a specific capacity of $366.9 \mathrm{mAh} / \mathrm{g}$ was maintained. When the current density returned to 1000 and $200 \mathrm{~mA} / \mathrm{g}$, the discharge capacities were 499.3 and $628.4 \mathrm{mAh} / \mathrm{g}$, respectively, which were only marginally lower than those initial values at the same current densities. The superior rate capability could be attributed to the intricate structure of SnS/NG, which enables it to withstand a harsh environment.

To further understand the superior cycle life of the SnS/NG anode, the morphologies of the samples after 100 cycles at $1000 \mathrm{~mA} \mathrm{~g}^{-1}$ were further investigated. As shown in Figure 7, SnS/NG electrodes maintained, for the most part, their structural integrity after 100 cycles, while SnS and SnS/G electrodes had obvious structural failure. Additionally, the cracks of the SnS electrodes were more 
severe than either the SnS/NG or SnS/G electrodes. For the cycled SnS/G hybrid, SnS clusters situated outside the graphene layers were visible due to a significant detachment from graphene sheets and subsequent aggregation into larger particles. In comparison, most of the SnS in SnS/NG were still well-dispersed, suggesting a strong attraction between them.
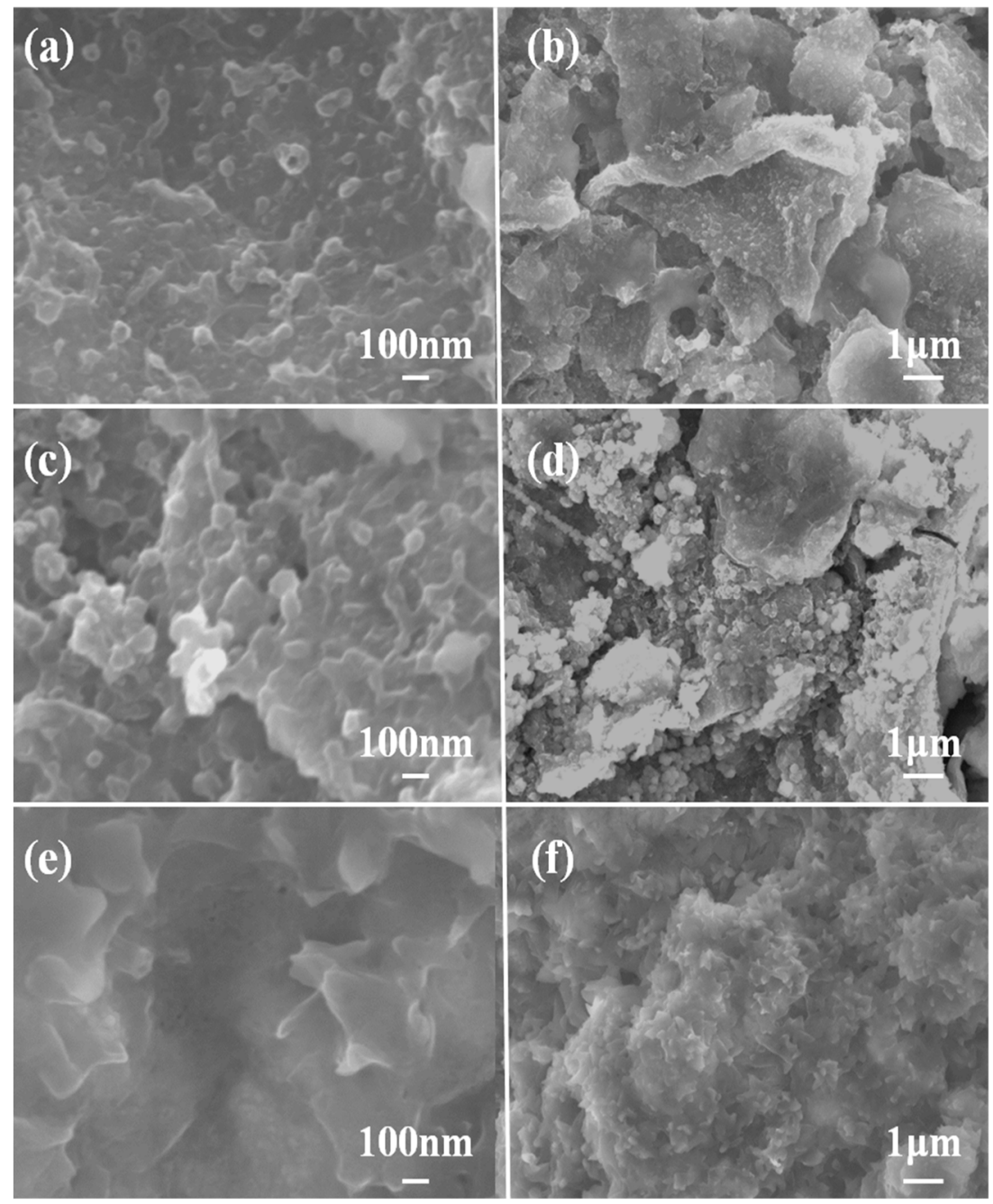

Figure 7. SEM images of (a,b) SnS/NG, (c,d) SnS/G, and (e,f) SnS after 100 cycles.

In order to further test the cycle performance of the SnS/NG obtained in our work as a potential anode material in sodium ion batteries, we compared the electrochemical performances of various SnS/graphene materials. The materials compared are listed in Table 1. Through contrast, we found that the cycle performance of the SnS/NG obtained in our work at high current density is excellent. Thus, our simple and gentle synthesis method may be used for reference in the preparation of other materials. 
Table 1. Comparison of cycling performance of SnS/NG with previously reported Sn-based anodes for sodium ion batteries (SIBs).

\begin{tabular}{|c|c|c|c|c|c|c|}
\hline Materials & Synthesis Method & $\begin{array}{c}\text { Reversible } \\
\text { Capacity } \\
\text { (mAh/g) }\end{array}$ & $\begin{array}{l}\text { Cycle } \\
\text { Life }\end{array}$ & $\begin{array}{c}\text { Current } \\
\text { Density } \\
(\mathrm{mA} / \mathrm{g})\end{array}$ & $\begin{array}{c}\text { Carbon } \\
\text { Content (\%) }\end{array}$ & Ref. \\
\hline $\begin{array}{l}\text { SnS nanoparticles } \\
\text { /reduced graphene } \\
\text { oxide }\end{array}$ & $\begin{array}{l}\text { In-situ growing }+ \\
\text { annealing }\left(700^{\circ} \mathrm{C}\right)\end{array}$ & 559 & 70 & 200 & 31.4 & [5] \\
\hline SnS@RGO & $\begin{array}{c}\text { Precipitation }+ \\
\text { annealing }\left(400^{\circ} \mathrm{C}\right)\end{array}$ & 386 & 100 & 100 & 21.9 & [17] \\
\hline SnS/G & $\begin{array}{c}\text { Hot water bath }+ \\
\text { annealing }\left(650^{\circ} \mathrm{C}\right)\end{array}$ & $<300$ & 30 & 50 & 15 & [12] \\
\hline hN-C@SnS & $\begin{array}{l}\text { Microwave reaction } \\
\quad+\text { annealing }\end{array}$ & 441.8 & 100 & 200 & 28.7 & [18] \\
\hline SnS/NG & $\begin{array}{c}\text { Hot water bath }+ \\
\text { annealing }\left(600^{\circ} \mathrm{C}\right)\end{array}$ & 417.8 & 100 & 1000 & 30.35 & $\begin{array}{l}\text { In our } \\
\text { work }\end{array}$ \\
\hline
\end{tabular}

\section{Conclusions}

In summary, SnS anchored to NG sheets was prepared in-situ using a facile, gentle, two-step process combining a hot water bath reaction and thermal annealing. Owing to its structural advantages, SnS/NG exhibited good cycling stability and excellent rate capability in comparison to pure SnS. With $35.35 \%$ content of graphene in the SnS/NG composite, the specific capacity was found to still be $417.8 \mathrm{mAh} / \mathrm{g}$ at $1000 \mathrm{~mA} / \mathrm{g}$ after 100 cycles, which reveals a high specific capacity and cycling stability. These excellent electrochemical properties demonstrate SnS may be applied in high-performance SIB fields. Furthermore, we analyzed the fast sodium storage kinetics of SnS/NG, providing some theoretical support for further study.

Author Contributions: Writing—original draft, N.-J.S.; Writing—review \& editing, C.M.

Funding: This research received no external funding.

Acknowledgments: We acknowledge the financial support from construction plan of "1331 engineering" photoelectric material innovation team of Jinzhong University, the open project of Key Laboratory of Materials for Energy Conversion and Storage of Shanxi Province (MECS2017002), the Shanxi "1331 Project" Key Innovative Research Team, Shanxi "1331 Project" Engineering Research Center (1331ERC), the Coal Seam Gas Joint Foundation of Shanxi (2015012016) and Shanxi "1331 Project" Engineering Research Center (PT201807). The authors thank the Scientific Instrument Center at Shanxi University for the kindly help in material characterizations.

Conflicts of Interest: The authors declare no conflict of interest.

\section{References}

1. Kundu, D.; Talaie, E.; Duffort, V.; Nazar, L.F. The Emerging Chemistry of Sodium Ion Batteries for Electrochemical Energy Storage. Cheminform 2015, 46, 3431-3448. [CrossRef]

2. Xu, Y.; Zhu, Y.; Liu, Y.; Wang, C. Electrochemical Performance of Porous Carbon/Tin Composite Anodes for Sodium-Ion and Lithium-Ion Batteries. Adv. Energy Mater. 2013, 3, 128-133. [CrossRef]

3. Datta, M.K.; Epur, R.; Saha, P.; Kadakia, K.; Park, S.K.; Kumta, P.N. Tin and graphite based nanocomposites: Potential anode for sodium ion batteries. J. Power Sources 2013, 225, 316-322. [CrossRef]

4. Wang, Y.X.; Lim, Y.G.; Park, M.S.; Chou, S.L.; Kim, J.; Liu, H.K.; Dou, S.X.; Kim, Y.J. Ultrafine SnO2 nanoparticle loading onto reduced graphene oxide as anodes for sodium-ion batteries with superior rate and cycling performances. J. Mater. Chem. A 2013, 2, 529-534. [CrossRef]

5. Li, J.; Zhao, X.; Zhang, Z. Ultradispersed nanoarchitecture of SnS nanoparticles/reduced graphene oxide for enhanced sodium storage performance. J. Colloid Interface Sci. 2017, 498, 153-160. [CrossRef] [PubMed]

6. Thangavel, R.; Samuthira, P.A.; Ramasamy, H.V.; Lee, Y.S. Rapidly Synthesized, Few-Layered Pseudocapacitive SnS2 Anode for High-Power Sodium Ion Batteries. ACS Appl. Mater. Interfaces 2017, 9, 40187-40196. [CrossRef] [PubMed] 
7. Xiong, X.; Yang, C.; Wang, G.; Lin, Y.; Ou, X.; Wang, J.H.; Zhao, B.; Liu, M.; Lin, Z.; Huang, K. SnS nanoparticles electrostatically anchored on three-dimensional $\mathrm{N}$-doped graphene as an active and durable anode for sodium-ion batteries. Energy Environ. Sci. 2017, 10, 1757-1763. [CrossRef]

8. Zhou, T.; Pang, W.K.; Zhang, C.; Yang, J.; Chen, Z.; Liu, H.K.; Gao, Z. Enhanced sodium-ion battery performance by structural phase transition from two-dimensional hexagonal-SnS 2 to orthorhombic-SnS. ACS Nano 2014, 8, 8323-8333. [CrossRef] [PubMed]

9. Choi, S.H.; Kang, Y.C. Aerosol-assisted rapid synthesis of SnS-C composite microspheres as anode material for Na-ion batteries. Nano Res. 2015, 8, 1595-1603. [CrossRef]

10. Wu, L.; Lu, H.; Xiao, L.; Qian, J.; Ai, X.; Yang, H.; Cao, Y. A tin(II) sulfide-carbon anode material based on combined conversion and alloying reactions for sodium-ion batteries. J. Mater. Chem. A 2014, 2, 16424-16428. [CrossRef]

11. Lu, Y.C.; Ma, C.; Alvarado, J.; Dimov, N.; Meng, Y.S.; Okada, S. Improved Electrochemical Performance of Tin-sulfide Anodes for Sodium-ion Battery. J. Mater. Chem. A 2015, 3, 16971-16977. [CrossRef]

12. Zhang, M.; Lei, D.; Yu, X.; Chen, L.; Li, Q.; Wang, Y.; Wang, T.; Cao, G. Graphene oxide oxidizes stannous to synthesize tin sulfide-graphene nanocomposites with small crystal size for high performance lithium ions batteries. J. Mater. Chem. 2012, 22, 23091-23097. [CrossRef]

13. Macarthur, D.M. The Hydrated Nickel Hydroxide Electrode Potential Sweep Experiments. J. Electrochem. Soc. 1970, 117, 422-426. [CrossRef]

14. Liu, J.; Jin, W.; Xu, C.; Hao, J.; Li, C.; Zhang, L.; Lin, J.; Shen, Z.X. Advanced Energy Storage Devices: Basic Principles, Analytical Methods, and Rational Materials Design. Adv. Sci. 2018, 5, 1700322. [CrossRef] [PubMed]

15. Augustyn, V.; Come, J.; Lowe, M.A.; Kim, J.W.; Taberna, P.L.; Tolbert, S.H.; Abruña, H.D.; Simon, P.; Dunn, B. High-rate electrochemical energy storage through $\mathrm{Li}^{+}$intercalation pseudocapacitance. Nat. Mater. 2013, 12, 518-522. [CrossRef] [PubMed]

16. Chen, C.; Wen, Y.; Hu, X.; Ji, X.; Yan, M.; Mai, L.; Hu, P.; Shan, B.; Huang, Y. $\mathrm{Na}^{+}$intercalation pseudocapacitance in graphene-coupled titanium oxide enabling ultra-fast sodium storage and long-term cycling. Nat. Commun. 2015, 6, 6929. [CrossRef] [PubMed]

17. Wu, L.; Lu, H.; Xiao, L.; Ai, X.; Yang, H.; Cao, Y. Improved sodium-storage performance of stannous sulfide@reduced graphene oxide composite as high capacity anodes for sodium-ion batteries. J. Power Sources 2015, 293, 784-789. [CrossRef]

18. Qin, B.; Zhang, H.; Diemant, T.; Dou, X.; Geiger, D.; Behm, R.J.; Kaiser, U.; Varzi, A.; Passerini, S. Exploring SnS nanoparticles interpenetrated with high concentration nitrogen-doped-carbon as anodes for sodium ion batteries. Electrochim. Acta 2019, 296, 806-813. [CrossRef] 